\title{
COMPETÊNCIA COMUNICATIVA: UMA COMPETÊNCIA ADMINISTRATIVA PARA O BIBLIOTECÁRIO UNIVERSITÁRIO CONTEMPORÂNEO
}

\section{COMPETÊNCIA COMUNICATIVA: UNA COMPETÊNCIA ADMINISTRATIVA PARA EL BIBLIOTECARIO CONTEMPORANEO}

Fabiana Menezes Santos da Silva - bibliofa@yahoo.com.br Mestranda em Ciência da Informação no Instituto Brasileiro de Informação em Ciência e Tecnologia (IBICT). Bibliotecária da Universidade Federal Fluminense (UFF)

Geni Chaves Fernandes - geni@centoin.com.br Doutora em Ciência da Informação Instituto Brasileiro de Informação em Ciência e Tecnologia (IBICT). Professora Adjunta da UNIRIO

Clóvis Ricardo Montenegro de Lima - clovis.mlima@uol.com.br Pós-doutor em Ciência da Informação pelo Instituto Brasileiro de Informação em Ciência e Tecnologia (IBICT). Pesquisador adjunto do IBICT.

\section{RESUMO}

Introdução: Nesta pesquisa indaga-se sobre competências administrativas que permitam aos bibliotecários gerenciarem suas bibliotecas nas atuais sociedades complexas, considerando-se que a própria Ciência Administrativa tem renovado seus aportes teóricos a fim de contemplar estruturas organizacionais mais flexíveis e participativas em seus arranjos e decisões.

Objetivo: Propor a competência comunicativa como elemento fundamental da competência administrativa de bibliotecários na contemporaneidade.

Metodologia: Revisão de literatura sobre os modos de gestão e as competências em administração de bibliotecários brasileiros e suas origens. Exame da literatura das alternativas 
administrativas, baseadas nas teorias de Habermas e Luhmann, que pretendem contemplar modos de gestão em sociedades complexas.

Resultados: Identificam-se limitações nas competências administrativas dos bibliotecários, ainda muito alicerçadas na emergência das bibliotecas públicas do século XIX, quando a formação de bibliotecários tomou o caminho de um saber técnico para o tratamento documental, que hoje precariza suas habilidades administrativas. Dentre as habilidades administrativas para reconfigurar bibliotecas contemporâneas se destaca, como um primeiro resultado desta pesquisa, a competência comunicacional, própria de uma Administração Discursiva, capaz de abrir espaços argumentativos para uma reconstrução racional e consensual de modelo de biblioteca próprio às sociedades complexas.

Conclusões: Os esforços para garantir competência administrativa do bibliotecário devem incluir sua competência comunicativa como habilidade indispensável para formulação de novos modelos de bibliotecas em sociedades complexas.

Palavras-chave: Competência administrativa. Competência comunicativa. Formação do bibliotecário. Jürgen Habermas. Niklas Luhmann.

\section{INTRODUÇÃO}

Este trabalho tem por tema central indagar a amplitude e os limites dos conhecimentos administrativos fornecidos nos cursos de biblioteconomia brasileiros aos futuros profissionais, que os permitam reconfigurar e gerir suas bibliotecas nas atuais sociedades complexas. A pesquisa tem em conta, de um lado, que as próprias teorias administrativas têm-se transformado a fim de fornecer elementos que possam otimizar as estruturas de gestão e favoreçam a produção colaborativa do conhecimento organizacional e, de outro, que não é suficiente melhorar as bibliotecas, mas reconstruílas, indagando-se, então, por quais possíveis caminhos.

Apresentam-se elementos que articulam reflexões da literatura sobre administração de bibliotecas brasileiras, elementos históricos e das teorias dos Sistemas de Luhmann e do Agir Comunicativo de Habermas, assim como a proposta da Administração Discursiva, que permitiram incluir no conceito de competência administrativa a competência comunicativa, que se apresenta como primeiro resultado de pesquisa.

Deve-se considerar que as características da sociedade contemporânea trazem consigo novos horizontes e expectativas. A expansão do processo produtivo, os novos relacionamentos e regras mundiais e a globalização, aliados aos avanços tecnológicos, possibilitam grandes mudanças que atingem de maneira diferenciada todas as esferas da sociedade.

A expectativa moderna do desenvolvimento de uma racionalidade que coloca na comunidade de eruditos, especialmente na ciência, a autoridade e responsabilidade para 
Fabiana Menezes Santos da Silva; Clóvis Ricardo Montenegro de Lima; Geni Chaves Fernandes Competência comunicativa: uma competência administrativa para o bibliotecário universitário contemporâneo

deliberar sobre os caminhos e soluções para a sociedade, transita ou pode transitar hoje para a responsabilidade do "todos nós", "[...] abrindo uma via de articulação entre a as universidades, a esfera pública e os mundos da vida." (GONZÁLEZ DE GÓMEZ, 2011, p. 236).

Não se trata aí de simplesmente reunir ou votar em opiniões, mas, conforme as proposta de Habermas, da abertura de espaços argumentativos em vista de construir coletivamente soluções tanto racionais como consensuais; soluções resultantes de uma comunicação em que todos foram ouvidos e igualmente considerados, portanto, com as quais todos estão comprometidos.

As universidades devem ser hoje, na concepção de González de Gómez, um espaço público de experimentação e aprendizagem social. Não lugares fechados donde se espera vir soluções, mas capazes de "[...] acompanhar e subsidiar as mudanças tecnológicas, econômicas, culturais, educacionais [...] num cenário de interdependência e pluralismo epistemológico e cultural”. (GONZÁLEZ DE GÓMEZ, 2011, p. 236-237)

As bibliotecas, especialmente as universitárias e públicas, são chamadas a renovar seu papel de articulação e mediação de diversos espaços públicos, abrindo um espaço comum de conhecimentos e saberes. Não apenas como locais onde se disponibilizam informações, mas de ações que permitam a permeabilidade e interatividade entre esferas sociais nos processos de aprendizagem coletiva, que caminhem para a reconstrução racional das regras que norteiam a sociedade.

Bibliotecas enquanto instituições sociais devem acompanhar e inovar em vista destas modificações sociais, econômicas e tecnológicas. Considera-se que a rigidez estrutural de oferta de conhecimentos prontos e de construção unilateral, criado em alicerce taylorista, não mais atende às atuais expectativas de construção de uma sociedade da informação, apontando-se a necessidade de sua reconfiguração e ampliação de seus espaços de ação. Neste sentido, os bibliotecários podem e devem se apropriar do leque de possibilidades que se colocam, de forma a assumirem integralmente o importante papel que lhes cabe, de viabilizar a produção, o acesso e o uso da informação em seus diferentes suportes.

Estão os bibliotecários preparados para reconfigurar suas bibliotecas de modo a conduzi-las a um espaço de interlocução entre as esferas da vida social? De um modo geral, ainda muito guiada pelo modelo moderno de biblioteca, grande parte dos profissionais encontra-se condicionada às atividades técnico-operacionais e pouco 
Fabiana Menezes Santos da Silva; Clóvis Ricardo Montenegro de Lima; Geni Chaves Fernandes Competência comunicativa: uma competência administrativa para o bibliotecário universitário contemporâneo

próximas às atividades de renovação gerencial. Obviamente o caminho que permita reconfigurar a biblioteca contemporânea é um caminho de aprendizagem, onde teorias e metodologias da administração são fundamentais. Não basta querer, é preciso saber fazer.

\section{DESENVOLVIMENTO E DEMANDAS ADMINISTRATIVAS NAS BIBLIOTECAS}

Em todas as sociedades o ser humano usa o conhecimento sobre os recursos da natureza de modo a desenvolver e melhorar as suas condições de vida. Castells (2001) afirma que cada modo de desenvolvimento é definido pelo elemento fundamental à produtividade no processo de produção. No modo de desenvolvimento industrial, o principal indutor de produtividade se encontra na introdução de novas fontes de energia e na capacidade de descentralização do seu uso ao longo dos processos de produção. $\mathrm{Na}$ sociedade da informação a fonte de produtividade se encontra nas tecnologias de geração de conhecimentos, de processamento da informação e de comunicação de símbolos.

Neste processo profundo de mudanças, as bibliotecas sofrem impactos tecnológicos, organizacionais e humanos. Entretanto, apesar das discussões sobre sentido das bibliotecas face aos novos contextos que se apresentam, os bibliotecários ainda hoje trabalham com fortes traços do modelo de organização que foi cunhado para atender o modo de organização social estabelecido na segunda metade do século XIX: a perspectiva de uma biblioteca pública emerge como fruto das ideias da Revolução Francesa e das necessidades advindas da Revolução Industrial. Naquela época a educação e qualificação para o trabalho nas indústrias e na administração pública é uma reivindicação cujo atendimento inclui as bibliotecas totalmente mantidas pelo Estado e para uso de toda sociedade.

As bibliotecas, até então prioritariamente voltadas para preservação de sabedorias do passado, devem assumir também a função pedagógica na disseminação de conhecimentos sempre renovados e que atendessem às esferas da cultura e da produção. No caso do modelo de biblioteca pública americana é necessário um grande aumento no contingente de bibliotecários, estruturando-se em 1876 o curso para sua formação: Columbia College Scholl of Library Economy (GALLARDO, 2001, p. 86-89). 
Fabiana Menezes Santos da Silva; Clóvis Ricardo Montenegro de Lima; Geni Chaves Fernandes Competência comunicativa: uma competência administrativa para o bibliotecário universitário contemporâneo

A biblioteca pública americana vinga pelos esforços políticos de bibliotecários frente ao governo, que também são responsáveis pela elaboração do seu modelo. sistema é planejado por bibliotecários intelectuais experientes como Thomas $\mathrm{H}$. William, Chales Ammi Cutter e Melvil Dewey, aliados a John Eaton, comissário da Educação nos Estados Unidos (MIKSA, 1983, p. 51-51), mas implantado por profissionais recémformados em nível técnico. É neste contexto que aparecem os primeiros códigos de classificação, os arranjos para organização das estantes e os serviços de referência (ALMEIDA JÚNIOR, 2000) revelando a demarcação das tarefas operacionais na organização da informação.

O caráter pedagógico da biblioteca pública do final do século XIX acopla com uma ciência cujos conhecimentos positivos a autorizam a recomendar caminhos e soluções para todos os campos da vida, com seu caráter normativo. A formação de bibliotecários em curso técnico é uma inovação alinhada ao modelo de produção fordista, onde cada qual deve saber fazer bem a sua parte.

Se a partir de 1930 a capacidade da ciência para responder sozinha que caminhos devem ser trilhados para atender às demandas sociais entra em xeque, "[...] colocando-se em suspenso as certezas iluministas da relação afirmativa entre progresso e racionalidade", nos anos 1960 é o próprio modo de produzir, conduzir e organizar o conhecimento que passa a ser tematizado, levando à preocupação, no final do século, com "[...] a forma de organização da aprendizagem social e da produção de conhecimentos sob novas premissas políticas e culturais [...] dando lugar a um viés éticopolítico." (GONZÁLEZ DE GÓMEZ, 2011, p.231-232).

As bibliotecas precisam, agora, lidar com estas novas possibilidades de acesso e uso da informação. É preciso migrar de um modelo tradicional de biblioteca centrado na disponibilidade e pensar em um modelo de biblioteca que prime pela acessibilidade (TARGINO, 2010) e, consideramos nós, por uma maior abertura do leque do que abriga como saberes.

Silva (2013), ao examinar a administração de bibliotecas universitárias, mapeia na literatura trabalhos que indicam fragilidade de conhecimentos administrativos, o que preocupa, porque estes conhecimentos são fundamentais para criar novos modelos de biblioteca e modo de agir do bibliotecário.

A falta de planejamento é responsável pela desconexão entre o que pensamos "poder fazer" e as atividades desenvolvidas nas bibliotecas (LEAL, 2010). Carvalho 
Fabiana Menezes Santos da Silva; Clóvis Ricardo Montenegro de Lima; Geni Chaves Fernandes Competência comunicativa: uma competência administrativa para o bibliotecário universitário contemporâneo

identifica como possível causa para esta desconexão a ausência de um perfil adequado, que pode ser explicado pela não apropriação das teorias administrativas por parte dos bibliotecários; revelando o pouco diálogo destes profissionais com estas teorias (CARVALHO, 2012).

Certamente uma considerável competência administrativa é necessária para reconfigurar bibliotecas à feição das sociedades complexas. Não se trata apenas de um saber que articule os processos em vista dos objetivos da biblioteca, mas de repensar seu papel e objetivos, portanto, criar novos processos, meios e procedimentos.

Trata-se de formar um profissional da informação cujo perfil incorpore habilidades e competências de comunicação e expressão, técnico-científicas, gerenciais, sociais e políticas. Isto porque em suas práticas profissionais os bibliotecários têm sido constantemente postos à prova na apropriação da informação e do conhecimento e no desenvolvimento de competências que atendam às novas realidades sociais e técnicas que emergem (CARVALHO, 2012).

\section{ELEMENTOS PARA UMA ADMINISTRAÇÃO DISCURSIVA}

A racionalidade tem sido uma questão central nas teorias da Administração desde o seu advento como campo de conhecimento sistematizado. A racionalidade administrativa também reduz as relações entre os sujeitos a uma dimensão objetiva. Os teóricos críticos têm sugerido que importante limitação do modelo burocrático reside na unilateralidade das relações interpessoais subjacente a esse tipo de organização, expressa especialmente na manipulação do significado em interações comunicativas quando se tem por objetivo o cálculo utilitário (LIMA; LIMA; MOREIRA, 2010, p. 670).

O uso da Teoria do Agir Comunicativo de Habermas constitui-se em poderoso instrumento de crítica da Administração. O abandono da visão funcionalista e instrumental pode ser compensado por uma avaliação e uma reconstrução dos modos de ação nos contextos organizacionais a partir dos recursos dos mundos da vida dos seus participantes, mais amplos e mais complexos do que a visão do observador nãoparticipante e do participante não-critico. A inclusão discursiva das perspectivas críticas pode contribuir para uma abordagem racional ampliada das situações organizacionais (LIMA; LIMA; MOREIRA, 2010, p. 689). 
Vizeu (2005, p. 11) observa que o foco na relação intersubjetiva entre o sujeito e o outro, dado na Teoria do Agir Comunicativo de Jürgen Habermas, oferece uma base explicativa para a ação do administrador, especialmente no que se refere as deficiências da teoria administrativa tradicional e às explicações mais comuns do fenômeno das organizações. Além disso, a Teoria do Agir Comunicativo também pode ser usada para uma crítica teórica na administração, que contribuam a discussão das questões da autonomia e da emancipação.

$\mathrm{Na}$ visão de Luhmann, os sistemas aparecem como uma tentativa de redução da complexidade existente no entorno, por meio do processo de seleção de possibilidades. $O$ processo seletivo ocorre pelo fato de que o sistema não suporta internalizar toda a complexidade existente no entorno. O sistema, então, seleciona apenas algumas possibilidades que the fazem sentido de acordo com a função que desempenha, tornando o entorno menos complexo para ele. Se selecionasse todas elas, não sobreviveria. Ao mesmo tempo em que a complexidade do entorno diminui, a sua aumenta internamente. Isso porque o número de possibilidades dentro dele passa a ser maior, podendo, inclusive, chegar a ponto de provocar sua diferenciação em subsistemas (KUNZLER, 2004, p. 124-125).

O agir comunicativo é um referencial adequado para a elaboração de novos critérios de racionalidade, de maneira a minimizar a contradição da forma de organização social na atualidade. Nesse sentido, a crítica à razão instrumental se desdobra na crítica ao modelo burocrático, no sentido de que a burocracia corresponde a reificação do ethos racional-instrumental na forma de um sistema auto-sustentado, capaz de coordenar e controlar a vida social tendo por base os critérios de utilidade. O processo de "colonização do mundo da vida" implica na substituição da regulação social mediada pela interação linguística, pela regulação do poder e do dinheiro, do Estado e da economia.

É a predisposição ao entendimento na interação comunicativa que permite a Habermas propor a reconstrução racional do ato de fala que permite a superação das contradições da racionalidade unilateral. Esta reconstrução racional é feita por meio da pragmática universal, um conceito que indica pretensões de validade universais pressupostas no ato de fala e que permitem o compartilhamento de significados entre os participantes da interação (VIZEU, 2005, p. 13).

A racionalidade comunicativa se caracteriza por ser uma racionalidade que tem como pressuposto fundamental a linguagem convertida em uma competência 
Fabiana Menezes Santos da Silva; Clóvis Ricardo Montenegro de Lima; Geni Chaves Fernandes Competência comunicativa: uma competência administrativa para o bibliotecário universitário contemporâneo

argumentativa que é capaz de produzir um entendimento recíproco entre os participantes da interação. Na racionalidade de cunho comunicativo interacional o mecanismo de coordenação das ações orientadas para o entendimento vem vinculado ao acordo como resultado, que a processualidade embutida no entendimento permite gerar mediante 0 reconhecimento intersubjetivo das pretensões de validez criticáveis que se fazem refletir através dos respectivos mundos a que se vinculam (BOLZAN, 2005, p. 96).

Os sujeitos que agem de modo comunicativo, ao se entenderem uns com os outros no mundo, também se orientam por pretensões de validez normativas. Não existe forma de vida sócio-cultural que não esteja pelo menos de modo implícito orientada para o seguimento do agir comunicativo com meios argumentativos - por mais rudimentar que tenha sido o desenvolvimento das formas de argumentação e por mais pobre que tenha sido a institucionalização dos processos discursivos de entendimento mútuo (HABERMAS, 2003, p. 123).

O princípio do discurso refere-se a um procedimento: o resgate discursivo de pretensões de validez normativa. Nessa medida, o discurso pode ser caracterizado como formal: ele não indica orientações de conteúdo, mas o processo do discurso prático. Esse não é um processo para a produção de normas justificadas, mas para o exame da validade de normas propostas ou hipotéticas. Sem o horizonte do mundo da vida de um determinado grupo social e sem conflitos de ação numa determinada situação, na qual os participantes consideram como sua tarefa a regulação consensual de uma matéria social controversa, não tem sentido querer empreender um discurso (HABERMAS, 2003, p. 126).

Bloquear a linguagem nas organizações é negar aos que participam dos processos produtivos a sua condição humana. É o uso da linguagem que permite a comunicação entre pessoas, incluindo a comunicação os que trabalham nas organizações. A comunicação é fundamental para que se produzam e compartilhem valores e conhecimentos. A perda da autonomia de falar nas organizações resulta no empobrecimento de valores e conhecimentos, e também na redução dos vínculos solidários entre os que trabalham. As reduções têm um custo: qualquer racionalização de processos, melhoria ou inovação nas organizações requer investimentos para a introdução de novos conhecimentos. O comando externo na perspectiva do observador implica em custos para apropriação, aceitação e legitimidade dos novos conhecimentos (LIMA; CARVALHO; LIMA, 2010). 
O Discurso tem papel ativo na transformação das organizações, valorizando e viabilizando expressão e comunicação entre os que participam dos processos produtivos. A ampliação da expressão das perspectivas e a viabilidade da comunicação que vão proporcionar a aprendizagem a partir dos próprios processos produtivos. O Discurso pode ser uma esfera de aprendizagem, pois o aprendizado é socialmente determinado por interações subjetivas e intersubjetivas entre os atores no processo de interação mediado pela linguagem em contextos específicos. A organização pode ser entendida como um sistema cognitivo capaz de sustentar processos de aprendizagem, isto é, as organizações que discutem são organizações capazes de aprender (LIMA; CARVALHO; LIMA, 2010).

\section{COMPETÊNCIA COMUNICATIVA NA ADMINISTRAÇÃO DE BIBLIOTECAS}

A questão-proposta conceitual que se coloca aqui, primeiramente em âmbito geral, e em seguida no âmbito da administração das bibliotecas indaga sobre participação efetiva dos sujeitos nas decisões de como deve ser o mundo em que vivem. Entretanto, esta competência não se reduz a escolha racional de meios e habilidades para informarse. A competência comunicativa está associada a fazer propostas e apresentar argumentações, escutar e considerar as propostas e justificativas dos demais interessados.

Nesta dinâmica entre linguagem e ação, atos de fala são considerados como tendo pretensões de validação universal que atendem a requisitos de verdade proposicional, sinceridade, retidão e inteligibilidade. O compartilhamento pleno de significados entre participantes de uma interação se dá quando todos os requisitos de validez são cumpridos e desta forma conduzem a dois tipos básicos de ação racional:

- a ação racional instrumental: [...] [onde] o atributo racional da ação se deve ao fato de esta ser justificada por fatos ou ter por base o seu resultado objetivo (êxito ou eficácia da ação), medido em termos de eficiência técnica no uso de meios;

- a ação racional comunicativa: [...] [onde] a legitimidade dos argumentos é obtida pela satisfação de todas as pretensões de validez. Neste tipo de ação, ocorre uma orientação dialógica, tendo em vista que a coordenação mútua é dada em função da capacidade comunicativa, recurso disponível a todos os participantes (VIZEU, 2005, p.14). 
Fabiana Menezes Santos da Silva; Clóvis Ricardo Montenegro de Lima; Geni Chaves Fernandes Competência comunicativa: uma competência administrativa para o bibliotecário universitário contemporâneo

$\mathrm{Na}$ ação comunicativa a racionalidade está fundamentada no processo de reconhecimento intersubjetivo que leva ao entendimento mútuo sobre algo no mundo. Na prevalência da orientação racional instrumental, a ação é estratégica. O atributo racional se dá na perspectiva de um dos participantes, mas o outro é apenas um meio para que se alcance o resultado esperado. Neste sentido, a comunicação é frequentemente distorcida em algumas de suas dimensões.

A utilização da linguagem para fins de entendimento está relacionada a um saber intuitivo que os indivíduos socializados possuem e que se revela como uma competência comunicativa adquirida pela inserção no mundo da vida e que os indivíduos utilizam na ação comunicativa.

A competência comunicativa consiste no domínio não-reflexivo (pré-teórico) de certas pressuposições que acompanham o entendimento lingüístico. Tais pressuposições têm caráter similar ao das regras gramaticais, que o indivíduo utiliza ao falar e que nem por isso lhe são conscientes. Portanto, da mesma forma como o indivíduo que fala é capaz de utilizar corretamente as regras gramaticais, mesmo sem dominá-las reflexivamente, assim também os sujeitos capazes de linguagem e de ação fazem uso de certas pressuposições pragmáticas ao utilizarem a linguagem voltada ao entendimento (HABERMAS, 1989a apud BOUFLEUER, 2001, p. 36).

A competência comunicativa apresentada por Prestes (1996) para tratar do papel da educação é apropriada por Dib (2013) para interpretar os desafios contemporâneos da universidade na formação não apenas de profissionais competentes em termos operacionais, mas também capazes de ações sociais significativas que precisam aliar crítica social e competência para ouvir e expor ideias e motivos para um entendimento mútuo (razão comunicativa).

Não se trata de um saber dado, inscrito em algum manual que se pode simplesmente lançar mão, ou de uma racionalidade inata que precisa ser simplesmente ativada, mas de competência que pode ser aprendida, de como estabelecer modos discursivos e inovadores de integração social.

As bibliotecas podem ser entendidas como sistemas, no sentido luhmanniano, em um acordo pragmático que reduz a complexidade ligada aos dispositivos, suportes e conteúdos informacionais. Esta redução da complexidade é inerente a construção de processos que viabilizam fluxos, acesso e uso. A redução opera por regras e limitações 
Fabiana Menezes Santos da Silva; Clóvis Ricardo Montenegro de Lima; Geni Chaves Fernandes Competência comunicativa: uma competência administrativa para o bibliotecário universitário contemporâneo

de inclusão, ordenamento e disponibilização, ou seja, nos meios que nos permitem lidar com a informação.

O aumento da complexidade do informacional e seu destaque na sociedade contemporânea fazem aparecer pressões sobre os sistemas. Há uma crescente tensão entre nossa capacidade de trabalhar com a complexidade e a necessidade do sistema tornar-se mais e mais complexo. Além disto, demandas humanísticas no mundo da vida entram em choque com os sistemas do poder e do dinheiro.

O agir do bibliotecário nesta sociedade contemporânea mais complexa depende obviamente de competências administrativas. Mas esta competência, embora necessária, não pode ser reduzida a uma competência instrumental e funcionalista. $O$ agir de um bibliotecário que responda às demandas contemporâneas requer esta competência comunicativa, normativa, que dá sentido ético as suas relações com o mundo. Não é um conhecimento dado, mas de uma aprendizagem de interlocução sobre como deve ser (DIB, 2013, p. 26).

$\mathrm{Na}$ proposta de uma Administração Discursiva (LIMA; CARVALHO, 2009; LIMA; LIMA; MOREIRA, 2010) a competência comunicativa se coloca como necessária para estabelecer um projeto em comum e consensual entre os interessados.

A competência requerida do bibliotecário é maior do que uma acumulação de teorias e metodologias da administração instrumental. Elas são necessárias, mas não são suficientes. Há outra competência racional integradora: comunicação, argumentação, discurso.

\section{CONSIDERAÇÕES FINAIS}

Este trabalho indaga sobre as competências administrativas de bibliotecários no contexto contemporâneo de sociedades complexas, que demandam novos modos de bibliotecas.

O caminho percorrido indica precariedade nos conhecimentos de Administração de bibliotecários brasileiros, mais aproximados da concepção moderna quando se constrói a exitosa biblioteca pública e se passa a formar bibliotecários como técnicos capazes de fornecer tratamento padronizado aos documentos para acesso a uma população recémurbanizada e proletarizada. 
Fabiana Menezes Santos da Silva; Clóvis Ricardo Montenegro de Lima; Geni Chaves Fernandes Competência comunicativa: uma competência administrativa para o bibliotecário universitário contemporâneo

Após mais de cem anos, com novos meios de comunicação e informação e uma nova ordem de organização social, as chamadas sociedades complexas, as habilidades administrativas dos bibliotecários precisam ser tanto reforçadas como modificadas, sem o que não serão possíveis criar novos modos de agir.

Destaca-se também a necessidade da competência comunicativa, habilidade que pode ser aprendida e aperfeiçoada. Esta disposição para argumentação e discussão é fundamental para o entendimento, mas não apenas para escolhas racionais.

Esta opção normativa pela escuta do outro é importante para uma critica da administração instrumental das organizações.

\section{REFERÊNCIAS}

ALMEIDA JÚNIOR, Oswaldo Francisco de. Profissional da informação: entre o espírito e a produção. In: VALENTIM, Marta Lígia Pomim (Org.). Profissionais da informação: formação, perfil e atuação profissional. São Paulo: Polis, 2000.

BOLZAN, José. Habermas: razão e racionalização. ljuí: Ed.Unijuí, 2005.

BOUFLEUER, José Pedro. Pedagogia da ação comunicativa: uma leitura de Habermas. 3. ed. ljuí: Ed. UNIJUÍ, 2001.

CARVALHO, Lidiane dos Santos. Informação e comunicação na administração das bibliotecas universitárias: entre as metáforas de Morgan e a visão de Luhmann. In: SEMINÁRIO NACIONAL DE BIBLIOTECAS UNIVERSITÁRIAS, 17., 2012, Gramado. Anais... Porto Alegre: Universidade Federal do Rio Grande do Sul, 2012. Disponível em: <http://www.snbu2012.com.br/anais/pdf/4REY.pdf>. Acesso em: 29 abr. 2013.

CASTELLS, Manuel. A sociedade em rede. 5. ed. São Paulo: Paz e Terra, 2001.

DIB, Simone Flaury. Administração discursiva nas bibliotecas universitárias brasileiras. 2013. Dissertação (Mestrado em Ciência da Informação) - INSTITUTO BRASILEIRO DE INFORMAÇÃO EM CIÊNCIA E TECNOLOGIA/Escola de Comunicação da Universidade Federal do Estado do Rio de Janeiro, Rio de Janeiro, 2013.

GALLARDO, José Adolgo Rodrígues. Formação humanística del bibliotecnólogo: hacia su recuperación. México: UNAM, 2001.

GONZÁLEZ DE GÓMEZ, Maria Nélida. A universidade e a "sociedade da informação". Revista Digital de Biblioteconomia e Ciência da Informação, Campinas, v. 9, n. 1, p. 225-242, jul./dez. 2011.

HABERMAS, Jurgen. Consciência moral e agir comunicativo. Rio de Janeiro: Tempo Brasileiro, 2003. 
Fabiana Menezes Santos da Silva; Clóvis Ricardo Montenegro de Lima; Geni Chaves Fernandes Competência comunicativa: uma competência administrativa para o bibliotecário universitário contemporâneo

KUNZLER, Caroline de Morais. Teoria dos sistemas de Niklas Luhmann. Estudos de Sociologia, Araraquara, v. 9, n. 16, p. 123-136, 2004.

LEAL, Janaina. Reengenharia em bibliotecas. Revista Digital de Biblioteconomia \& Ciência da Informação, Campinas, v. 8, n. 1, p. 12-20, jul./dez. 2010. Disponível em: $<$ http://www.brapci.ufpr.br/documento.php?dd0=0000009043\&dd1=2920a $>$. Acesso em: 23 nov. 2012.

LIMA, Clóvis Ricardo Montenegro de; CARVALHO, Lidiane; LIMA, José Rodolfo Tenório. Notas para uma administração discursiva das organizações. DataGramaZero - Revista de Ciência da Informação, Rio de Janeiro, v. 11, n. 6, dez. 2010.

LIMA, Clóvis Ricardo Montenegro; CARVALHO, Lidiane dos Santos. Informação, comunicação e inovação: gestão da informação para a inovação em uma organização complexa. Informação \& Informação, Londrina, v. 14, n. 2, p. 1-2, jul./dez., 2009.

Disponível em:

$<$ http://www.brapci.ufpr.br/documento.php?dd0=0000009043\&dd1=2920a $>$. Acesso em: 25 abr. 2013.

LIMA, Clóvis Ricardo Montenegro; LIMA, José Rodolfo Tenório; MOREIRA, Fernanda Kempner. Problematização e racionalização dos processos produtivos em organizações. Revista de Gestão da Tecnologia e Sistemas de Informação, São Paulo, v. 7, n. 3, p. 667-690, 2010.

LUHMANN, Niklas. Introdução à teoria de sistemas. Petrópolis: Vozes, 2010.

MIKSA, Francis. Melvil Dewey and the corporate ideal. In: STEVENSON, G. KREMERGREENER, J. (Org.). Melvil Dewey: the men and the classification. Albany: Forest Press, 1983. p. 49-100.

PRESTES, Nadja Hermann. Educação e racionalidade: conexões e possibilidades de uma razão comunicativa na escola. Porto Alegre: EDIPUCRS, 1996. (Filosofia, 36).

SILVA, Fátima Santana da. Administração de bibliotecas em instituições privadas de ensino superior: uma abordagem discursiva a partir das novas demandas de acesso e uso da informação. 2013. Dissertação (Mestrado em Ciência da informação) INSTITUTO BRASILEIRO DE INFORMAÇÃO EM CIÊNCIA E TECNOLO̧GIA/Escola de Comunicação da Universidade Federal do Estado do Rio de Janeiro, Rio de Janeiro, 2013.

TARGINO, Maria das Graças. A biblioteca do século XXI: novos paradigmas ou meras expectativas? Informação \& Sociedade: Estudos, João Pessoa, v. 20, n. 1, p. 39-48, jan./abr. 2010. Disponível em:

<www.ies.ufpb.br/ojs/index.php/ies/article/download/2645/3418>. Acesso em: 30 de maio 2013.

VIZEU, Fabio. Ação comunicativa e estudos organizacionais. Revista de Administração de Empresas, São Paulo, v. 45, n. 4, p. 10-21, out./dez. 2005. 
Fabiana Menezes Santos da Silva; Clóvis Ricardo Montenegro de Lima; Geni Chaves Fernandes Competência comunicativa: uma competência administrativa para o bibliotecário universitário contemporâneo

\title{
Title
}

Communicative competence: an administrative competence for contemporary librarian

\begin{abstract}
Introduction: This ongoing study asks about administrative skills to enable librarian manager's their libraries on current complex societies, considering that Administrative Science has renewed its theoretical framework to conceive organizational structures more flexible and collaborative in their arrangements and decisions.

Objective: Propose the communicative competence as a fundamental element to contemporary administrative librarianship competence.

Methodology: Literature review on management methods and Brazilian librarians skills in administration and their origins. Literature review on managing alternatives based on the theories of Habermas and Luhmann to contemplate ways of managing in complex societies.

Results : Limitations in librarians administrative skills were detected. Their model methods still grounded in public libraries, as they emerged in nineteenth century, when the training of librarians took the path of technical work on documentary process. Actually it becomes precarious their management skills. Among the administrative skills to reconfigure libraries contemporary shows up, as a first result of this research, the communicative competence, as a typical skill of a Discursive Management, which open argumentative spaces towards a rational and consensual library model reconstruction fitting to complex societies. Conclusions: Efforts to ensure librarians administrative competence should include their communicative competence as a fundamental skill to formulate new models for libraries in complex societies.
\end{abstract}

Keywords: Administrative competence. Communicative competence. Librarian formation. Jürgen Habermas. Niklas Luhmann.

\section{Título}

Competência comunicativa: una competência administrativa para el bibliotecario contemporaneo

\section{Resumen}

Introducción: En este estudio en curso se pregunta acerca de las habilidades administrativas que permitan a los bibliotecarios administrar sus bibliotecas en las sociedades complejas actuales, teniendo en cuenta que la ciencia administrativa ha renovado su marco teórico para concebir estructuras organizativas más flexibles y participativas en sus arreglos y decisiones.

Objetivo: Proponer la competencia comunicativa como un elemento fundamental de la competencia administrativa bibliotecológica contemporánea.

Metodología: Revisión de la literatura en métodos de gestión y habilidades en la administración de bibliotecarios brasileños y sus orígenes. Revisión de la literatura acerca de alternativas administrativas basadas en las teorías de Habermas y Luhmann, que buscan contemplar formas de gestión en las sociedades complejas.

Resultados: Limitaciones en las habilidades administrativas de los bibliotecarios fueran detectadas, porque todavía restan muy basadas en las emergentes bibliotecas públicas del siglo XIX, cuando la 
Fabiana Menezes Santos da Silva; Clóvis Ricardo Montenegro de Lima; Geni Chaves Fernandes Competência comunicativa: uma competência administrativa para o bibliotecário universitário contemporâneo

formación de los bibliotecarios tomó el camino de un saber técnico de tratamiento de los documentos que reduce su capacidad de gestión. Entre las competencias administrativas para reconfiguraren a las bibliotecas presentase como primer resultado de esta investigación la competencia comunicativa, conforme la Administración Discursiva, capaz de abrir espacios argumentativos para una reconstrucción racional y consensual de un modelo de biblioteca propia a las sociedades complejas.

Conclusiones: Los esfuerzos para asegurar la competencia administrativa del bibliotecario deben incluir su competencia comunicativa, y la habilidad necesaria para formular nuevos modelos de bibliotecas a las sociedades complejas.

Palabras clave: Competencia administrativa. Competencia comunicativa. Formación del Bibliotecario. Jürgen Habermas. Niklas Luhmann.

Recebido em: 10.09.2013

Aceito em: 30.11 .2013 